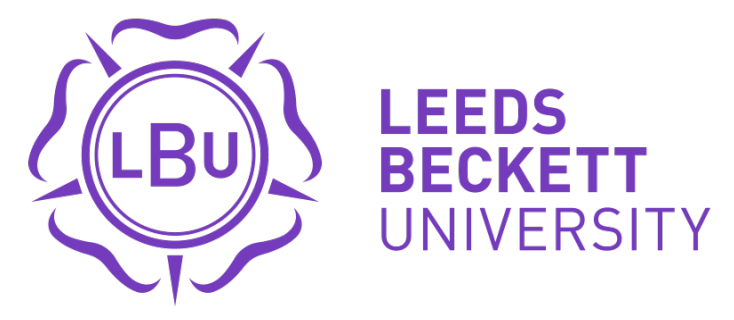

Citation:

Fabri, M and Fenton, G and Andrews, PCS and Beaton, MC (2020) Experiences of higher education students on the autism spectrum: Stories of low mood and high resilience. International Journal of Disability, Development and Education. ISSN 1034-912X DOI: https://doi.org/10.1080/1034912X.2020.1767764

Link to Leeds Beckett Repository record:

https://eprints.leedsbeckett.ac.uk/id/eprint/6612/

Document Version:

Article (Accepted Version)

This is an Accepted Manuscript of an article published by Taylor \& Francis in International Journal of Disability, Development and Education on 24 May 2020, available online: http://www.tandfonline.com/10.1080/1034912X.2020.1767764

The aim of the Leeds Beckett Repository is to provide open access to our research, as required by funder policies and permitted by publishers and copyright law.

The Leeds Beckett repository holds a wide range of publications, each of which has been checked for copyright and the relevant embargo period has been applied by the Research Services team.

We operate on a standard take-down policy. If you are the author or publisher of an output and you would like it removed from the repository, please contact us and we will investigate on a case-by-case basis.

Each thesis in the repository has been cleared where necessary by the author for third party copyright. If you would like a thesis to be removed from the repository or believe there is an issue with copyright, please contact us on openaccess@leedsbeckett.ac.uk and we will investigate on a case-by-case basis. 


\title{
Experiences of higher education students on the autism spectrum: Stories of low mood and high resilience
}

\author{
Marc Fabri* $^{\mathrm{a} *}$, Grania Fenton ${ }^{\mathrm{b}}$, Penny C.S. Andrews ${ }^{\mathrm{a}}$ and Mhairi C. Beaton ${ }^{\mathrm{c}}$ \\ ${ }^{a}$ Leeds School of Arts, Leeds Beckett University, Leeds, UK; \\ ${ }^{b}$ School of Social Sciences, Leeds Beckett University, Leeds, UK; \\ ${ }^{c}$ Carnegie School of Education, Leeds Beckett University, Leeds, United Kingdom
}

Increasing numbers of students on the autism spectrum enter higher education (HE), hoping to develop their skills and independence. However, many find it difficult to transition to and succeed in this environment, and the support provided by universities can be inconsistent as highlighted by a recent review. This study explores the personal experiences of 16 students with autism from four Western countries, focusing on successes and challenges. Using thematic analysis, four core themes were identified: choices and aspirations, being at university, support provisions, and specific recommendation. Anxiety, depression and mood difficulties were frequently reported. The importance of positive personal relationships, and the need for autism training and empathy amongst support professionals was highlighted. Further, there is a need for universities to provide joined up academic and social support and to implement reasonable adjustments in an inclusive way, thereby avoid stigmatizing the student. Whilst negative experiences dominated, there were notable examples of good support practice and high levels of personal resilience and determination amongst the participants. To inform future practice, we conclude by offering a set of recommendations for educators, support professionals and for students on the autism spectrum.

Keywords: autism, higher education, transition, disability support, thematic analysis 


\section{Introduction}

Autism is a lifelong developmental condition that affects how a person communicates with and relates to other people, and the world around them. Estimates regarding the prevalence of autism in the population vary from 1\% (Brugha et al., 2012) to 1.7\% (CDC, 2018), with approximately half of those on the autism spectrum having no associated learning difficulty (Fombonne, 2009) and therefore the potential to enter and succeed in higher education study.

Indeed, many young people with autism have specific strengths that are considered conducive to academic study, e.g. an ability to maintain intense focus, attention to detail, to think rationally and logically, good memory, to adopt unconventional angles in problem solving or to spot errors that others may overlook (cf. Plaisted Grant \& Davis, 2009; Russell et al., 2019). However, many find it difficult to succeed in Higher Education (Anderson et al. 2017), missing out on reaching their full potential, living independent lives and contributing fully to society. It is estimated that the lifetime economic costs of supporting a person with autism (without learning difficulty) who is able to work but not in employment is around $£ 1.2 \mathrm{~m}$ (Rogge \& Janssen, 2019), therefore supporting this group of students should be a priority.

Whilst universities have generally seen a year-on-year increase in the number of students with autism (cf. HESA, 2018; Bakker et al., 2019), support can be inconsistent and awareness of what autism is, and how it may affect the individual's university experience, varies significantly (Anderson et al., 2017; Gelbar et al., 2014). It has been acknowledged that supporting this group of students may be challenging given their characteristics, interests and needs (Ward \& Webster, 2018). Lambe et al (2019) point out that there have been a number of interventions and programs to help students with autism succeed at university. However, often the support offered is not specific to autism, instead it may have been adapted from other programs such as dyslexia support which may not meet the needs of students with autism (Ness, 2013). Further, whilst many universities provide good traditional academic support, non-academic support for students with autism is often inadequate or non-existing (Anderson et al., 2017), yet much needed. It has been well established that students with autism are more likely to struggle in non-academic areas of university life, particularly related to their social interactions, sense of belonging and emotional well-being (Cai \& Richdale, 2016; Madriaga, 2010; Milton \& Sims, 2016). 
Wehman et al. (2014) express concern that support strategies may confirm deficits rather than focus on students' abilities and high potential as learners - a side effect of the predominant approach of arranging support in the form of reasonable adjustments, which by their very nature focus on identifying deficits and weaknesses.

\section{Research Aims}

The aim of this paper was to gain an understanding of the experiences of students with autism in HE, responding to a gap in research identified by Gelbar et al. (2014). Further, as Anderson et al. (2017) have recognized, more research with both successful students and drop-outs is required, and this study goes some way towards that. Finally, we formulate a set of evidencebased recommendations to inform future practice in academic, social and transition support, as called for by Gelbar et al. (2014).

Whilst this is a multi-national study with participants originating from several Western countries, the aim was to look for common experiences rather than identifying national differences. Nevertheless, the study adds an important international dimension to a research area that tends to look at national contexts only. Whilst the authors recognize that the sample size was not extensive, analysis would indicate that the commonalities of response across the participating countries merits consideration.

The project team included two researchers with autism who were directly involved in formulating the research aim and developing the research instruments. One of these researchers (author 3) was also involved in study implementation and results interpretation.

\section{Methods}

\section{Measures}

A questionnaire was designed, consisting of mostly open questions about people's personal experiences when applying to, or being at, university. Questions covered the challenges they faced, support they received and how this affected them in the past as well as at the time of the interview. Questionnaires could be completed either by the person with autism, or by a trusted person who would complete it together with the person with autism. Questions could be responded to online or via a face-to-face interview, depending on preference.

\section{Recruitment}

Participants were recruited via existing contacts within the research team and via social media services, forums and online mailing lists frequented by specific participant groups. Participants self-selected based on reporting that a) they had an autism diagnosis and b) that they currently attended university or had attended university in the past. All participants provided informed written consent. 


\section{Procedure}

The survey was conducted simultaneously in several languages over a period of 3 months. Data was collected using the online survey system Snap v10 (Snap Surveys, 2010) which allows multi-language responses to be collated in a single database. No participant took up the offer of a face-to-face interview. Non-English responses were translated by native speakers of the respective languages (Spanish and Finnish). All data were imported into NVivo qualitative data analysis software (QSR International, 2015) for further analysis.

\section{Analysis}

Principles of thematic content analysis were rigorously and systematically applied to the qualitative data, using methods recommended by Braun and Clarke (2006). These methods allow qualitative data to be analyzed in a theoretical and methodologically sound manner. In accordance with these and other recommendations (Elliott et al., 1999), the following process was followed:

1. Familiarization with the data and recording initial draft codes.

2. Systematically generating initial codes, ensuring equal attention to each data item.

3. Collating codes into initial themes.

4. Reviewing themes to ensure internal homogeneity and external heterogeneity.

5. Validating themes across the entire data set.

6. Generating a thematic mind-map of themes.

7. Defining and naming themes and sub-themes to ensure concision.

8. Selecting data extracts to ensure data had not just been paraphrased or described. A small proportion of the collected data was of quantitative nature (e.g. participant demographics), which was analyzed using descriptive methods.

\section{Credibility Check}

Braun and Clarke (2006) and Elliott et al. (1999) recommend a number of ways in which the qualitative analysis of data can be enhanced. In line with this, we ensured that the questions asked of participants comprised mostly open-ended questions, so participants influenced the generated data; data interpretation was regularly discussed with another experienced researcher (not a co-author) to ensure inter-rater reliability and allow for a structured, iterative generation of codes and themes; and finally data extracts are provided within the results section to provide context and illustrate how codes were grouped into themes.

Further, as with all qualitative research, there is a possibility that the interpretation of results was influenced by the researchers' personal biases. The authors tried to mitigate 
against this by consciously stating their positionalities and then regularly validating themes and data interpretations with each other, as recommended by Elliott et al. (1999):

1. Author 1 is a researcher and lecturer who regularly teaches students with autism on creative technology courses.

2. Author 2 is a clinical psychologist and has been involved in the assessment and therapeutic support of young people with autism.

3. Author 3 is a researcher with autism and a disability activist who has experience of both dropping out of university and successfully completing degree courses.

4. Author 4 is a researcher and lecturer in special educational needs and inclusion who regularly teaches students specializing in autism provision.

To mitigate the authors' experiences and beliefs impacting on the data analysis, an independent rater was involved in generating initial codes and generating and validating themes. This also ensured inter-rater reliability. It is hoped that this procedure ensured that data have been correctly represented and interpreted and that the results reported do not simply represent a version of the researchers' own views, but that they have indeed been enhanced by previous experiences.

\section{Results}

\section{Participant characteristics}

16 participants took part in the study (see Table 1 for characteristics). Specific data on race, ethnicity or socioeconomic status were not recorded. Of these 16 participants, 9 completed the questionnaire unaided (56\%) and 7 completed the questionnaires with a trusted person $(44 \%)$.

Table 1: Participant demographic and HE experiences

\begin{tabular}{|l|l|l|l|l|l|l|}
\hline P\# & $\begin{array}{l}\text { Gender } \\
\text { of } \\
\text { autistic } \\
\text { person }\end{array}$ & Type of story & $\begin{array}{l}\text { Age } \\
\text { when } \\
\text { starting } \\
\text { HE study }\end{array}$ & $\begin{array}{l}\text { Resi- } \\
\text { dence }\end{array}$ & $\begin{array}{l}\text { Un- } \\
\text { aided }\end{array}$ & $\begin{array}{l}\text { Relation } \\
\text { ship of } \\
\text { trusted } \\
\text { person }\end{array}$ \\
\hline $\mathbf{1 .}$ & Female & Problem & 20 & UK & Yes & $\mathrm{n} / \mathrm{a}$ \\
\hline $\mathbf{2 .}$ & Female & Elements of both problem and success & 25 & Finland & Yes & $\mathrm{n} / \mathrm{a}$ \\
\hline
\end{tabular}




\begin{tabular}{|c|c|c|c|c|c|c|}
\hline 3. & Male & Elements of both problem and success & Unknown & Spain & Yes & $\mathrm{n} / \mathrm{a}$ \\
\hline 4. & Male & Success & 18 & Spain & Yes & $\mathrm{n} / \mathrm{a}$ \\
\hline 5. & Male & Elements of both problem and success & 26 & Finland & Yes & $\mathrm{n} / \mathrm{a}$ \\
\hline 6. & Female & Elements of both problem and success & 21 & Finland & Yes & $\mathrm{n} / \mathrm{a}$ \\
\hline 7. & Female & Elements of both problem and success & 19 & Finland & Yes & $\mathrm{n} / \mathrm{a}$ \\
\hline 8. & Female & Elements of both problem and success & 21 & Finland & Yes & $\mathrm{n} / \mathrm{a}$ \\
\hline 9. & Male & Elements of both problem and success & 19 & Finland & Yes & $\mathrm{n} / \mathrm{a}$ \\
\hline 10. & Male & Problem & 18 & Spain & No & Therapist \\
\hline 11. & Male & Elements of both problem and success & 18 & Spain & No & $\begin{array}{l}\text { Psycholo } \\
\text { gical and } \\
\text { educatio } \\
\text { nal } \\
\text { support }\end{array}$ \\
\hline 12. & Male & Problem & Unknown & Finland & No & Mother \\
\hline 13. & Female & Elements of both problem and success & 18 & Spain & No & $\begin{array}{l}\text { Psycholo } \\
\text { gist }\end{array}$ \\
\hline 14. & Male & Success & 23 & Spain & No & $\begin{array}{l}\text { Psycholo } \\
\text { gist }\end{array}$ \\
\hline 15. & Male & Elements of both problem and success & 19 & Spain & No & Teacher \\
\hline 16. & Female & Success & 24 & USA & No & Mother \\
\hline
\end{tabular}

\section{Gender and Age}

Participants with autism comprised slightly more males $(n=9 ; 56 \%)$ than females $(n=7 ; 44 \%)$.

All participants were asked what age they were when starting HE study. Data were available for 14 of the 16 participants (87.5\%) and the average age was 20.64 years, age range $18-26$, standard deviation 2.79 . 
Type of Story

Participants were asked to indicate whether the story they were about to tell was classified as a 'success' story, a 'problem' story, or whether it had elements of both. The majority reported elements of both $(\mathrm{n}=10 ; 63 \%)$, with 3 reporting a success story and 3 a problem story.

\section{Autism Diagnosis}

Most participants reported having had a formal diagnosis of an autism spectrum condition, obtained from a medical professional $(63 \% ; n=7$ psychiatrists and $n=3$ neurologists) or a psychologist $(31 \% ; n=5)$. One person reported that educational staff had identified the condition.

\section{Relationship to Trusted Person}

Where a trusted person helped completing the questionnaire, they were asked to indicate their relationship to the person with autism. The majority had a professional relationship with the individual $(\mathrm{n}=5 ; 71 \%)$. The remaining 2 were a parent.

\section{Language}

$50 \%(n=8)$ of participants completed the questionnaires in Spanish, followed by Finnish $(38 \% ; n=6)$, then English $(12 \% ; n=2)$.

\section{Overview of Key Themes}

Following Braun and Clarke (2006), the thematic analysis led to the identification of four participant-generated key themes around positive and negative HE experiences (see Table 2). These are explored in detail in the following sections: 
Table 2: Key themes and sub-themes. The numbers $(n, m)$ refer to $n=$ number of participants talking about this sub-theme, $m=$ number of times it was talked about.

\begin{tabular}{|c|c|c|c|}
\hline $\begin{array}{l}\text { Choices and } \\
\text { Aspirations }\end{array}$ & $\begin{array}{l}\text { Being at } \\
\text { University }\end{array}$ & $\begin{array}{l}\text { Support } \\
\text { Provision }\end{array}$ & $\begin{array}{l}\text { Specific } \\
\text { Recommendations }\end{array}$ \\
\hline $\begin{array}{ll}\text { - } & \text { Aspirations and } \\
\text { expectations } \\
(9,27) \\
\text { - } & \text { Motivations for } \\
& \text { studying }(5,5) \\
- & \text { Choosing a } \\
& \text { subject }(6,9) \\
- & \text { Practicalities of } \\
& \text { the application } \\
& \text { process }(2,3)\end{array}$ & $\begin{array}{ll}- & \text { Mood difficulties } \\
& (13,28) \\
- & \text { Relationships and } \\
& \text { social }(11,25) \\
- & \text { Academic } \\
& \text { challenges } \\
& (11,33) \\
- & \text { Practical } \\
& \text { difficulties }(5,5) \\
- & \text { Discrimination } \\
& \text { and abuse }(6,6) \\
- & \text { Coping strategies } \\
& (9,19) \\
- & \text { Outcomes }(13,29)\end{array}$ & $\begin{array}{ll}- & \text { Good support } \\
& \text { practice }(12,45) \\
- & \text { Gaps in support } \\
& (10,24) \\
- & \text { Ineffective } \\
& \text { support }(5,7) \\
- & \text { Importance of } \\
& \text { diagnosis }(6,11)\end{array}$ & $\begin{array}{ll}\text { - } & \text { Positive } \\
& \text { relationships } \\
& (11,25) \\
\text { - } & \text { Individual needs } \\
& (7,13) \\
-\quad & \text { Academic } \\
& \text { adjustments }(4,6)\end{array}$ \\
\hline
\end{tabular}

\section{Theme 1: Choices and Aspirations}

Participants described the career and employment aspirations they had, as well as their motivations for studying. Four sub-themes were identified: 1) motivations for studying, 2) practicalities of the application process, 3) aspirations and expectations, and 4) suitability of study subject.

Participants talked about starting university and what they hoped to achieve. This involved motivations for choosing a particular study topic, which were positive for some (personal fulfilment) and negative for others (the perception that the options were limited). Several participants spoke about their expectations of the university experience, and of future ambitions:

'[previous studies] sparked a wish to develop further.'(P7)

'She wanted to study ... to prove her worth and to feel that she could do the same as others.'(P13) 
Two participants talked about anxiety related to passing university entrance exams: 'uncertainty about my future, the stress and the extreme pressure caused me some anxiety. I even thought I would kill myself if I did not get in.' (P7)

Most participants described issues relating to their choice of study subject. These were related to realizing early on that the chosen subject was not suitable or realizing later in the course that professional requirements of the field made it hard to practice in the chosen profession. For example, one participant dropped out during the practice element of their teacher training due to difficulties in managing social relationships with others.

\section{Theme 2: Being at University}

Participants covered all aspects of the student experience, difficulties encountered and what happened in the end. The nature of responses was predominantly negative, though a quarter of participants shared positive strategies for how to cope with difficulties, and final outcomes were more evenly balanced.

\section{Difficulties encountered}

Participants described a myriad of difficulties associated with being at university. Low mood, anxiety and feelings of hopelessness were commonly reported $(n=13 ; 82 \%)$ and frequently connected to relational and social difficulties:

I found the whole combination of being unable to follow lectures (or even conversations), the humiliation of failing exams in subjects I'd previously scored high marks in, plus the accompanying social isolation, to (sic.) much to bear. I became increasingly tearful and had meltdowns. '(P1)

'I was left out of the social circles and the silent knowledge conveyed through them.' (P7)

[as an autistic person] 'you become excluded from everything.'(P2)

Difficulties regarding the studying experience were mainly related to group work, with participants describing their preferences for peaceful environments where they could study alone, and didactic methods being preferred over experiential learning.

\section{'I knew that independent mathematical work and following lectures}

and demonstrations suit me, but large projects, especially when carried out as group work, do not.'(P9) 
Difficulties in planning study schedules and managing conflicting demands due to a perceived lack of timing and organization skills were also reported.

'I did not know how to prioritise my schedule properly, because I did not know that I had any special problems that would require a more detailed timetable to structure my work.' (P3)

Several participants described difficulties with unplanned changes to timetables or rooms, and feeling overstimulated due to noise and the general busyness of the environment. Coping with the demands of working and studying at the same time, financial worries or ensuring self-care whilst studying were also referred to.

Whilst some participants spoke of how they had coped with such difficulties by using alcohol or withdrawing, others described more positive mechanisms such as social networks, exercise, relaxation and religion.

\section{Outcomes}

When asked about how participants felt about the 'conclusion' of their university experience, they again described negative as well as positive outcomes. For some, graduating became the sole goal, with somewhat broken future aspirations:

'The experience [of studying abroad] turned out to be an unmitigated disaster. I've gone from being classified as a talented linguist at school to someone for whom languages are no more than an intellectual hobby.' (P1)

'I graduated, because I wanted to graduate. I was desperate. I no longer had any plans for the future, no hope that I could live on.' (P2)

Where autism-related issues had affected their performance, some participants were advised by their university to take time out or to discontinue their studies - triggering a sense of defiance:

$$
\begin{gathered}
\text { '[I] was advised to leave my studies; eventually [I] went to other } \\
\text { universities ... to collect enough study credit to equate to a bachelor } \\
\text { degree.' (P5) }
\end{gathered}
$$

At the end of their studies, participants reflected on friendships and the advantages of being socially connected at university. Several participants had hoped to make friends but were disappointed: 
'I expected to find some friends during my time at university,

but I never did. '(P2)

Those who did make friends thrived on that, although repeating a year or studying abroad undermined the positive effects.

\section{Theme 3: Support Provision}

Participants spoke at length about the support offered. The following sub-themes were identified: 1) good support practice, 2) gaps in support, 3) ineffective support, and 4) the importance of diagnosis.

\section{Good Support Practice}

Participants commonly described positive relationships as having been inherently supportive $(63 \%, n=10)$, whether with peers, lecturers, mentors, mental health professionals or family members. Supervision, feedback on performance and flexible studying arrangements were amongst the types of academic support described in a positive manner. Feeling that others were aware of what it meant to be on the autism spectrum, and were able to act accordingly, seemed to be extremely helpful.

'I talked to the teachers and my fellow students openly about my life, even my diagnosis. For me this was ... a crucial change for the better' (P6)

Participants also described how good communication and effective co-ordination between the numerous groups involved in academic or pastoral support helped them:

'co-ordination between the university and the care service for autistic people, where the same consistent provision is given to an autistic student, is very important'(P11)

'I was able to mediate for him so that both teachers and student peers could understand his behaviour. ... All this has been very positive.' (P15)

Participants liked general 'skills' development regarding self-esteem, stress management, confidence building and effective group work:

'I got personal help with my problems, regarding special study arrangements as well as life in general, which meant a lot to me.'(P7)

Executive functioning skills, including organization and planning skills as well as skills in inhibiting responses (e.g. knowing when it might be appropriate, or not, to interrupt a 
lecture) were also described as positive modes of support, which helped participants engage in HE.

Gaps in Support

Gaps in support often related to poor communication, missing or unclear guidance.

Participants found that information was conveyed through social circles that they were not a part of or had not been informed about. Lack of support in developing language, social and executive function skills were also described. Participants felt academic support was lacking in terms of assignment feedback as well as staff availability.

'The worst were the assignments, because I knew nothing about how they should be done and the information was difficult to find.'(P9)

'... studying and self-assessment were difficult

because there was hardly ever any feedback ... I had

no single familiar person or office that I could turn to for advice' (P7)

Participants spoke of financial constraints impacting the types of support available, feeling ignored by support services, and of lacking in confidence to seek support:

'...you think of course that so-called experts know better than you ... so you do not easily question, you daren't demand more meetings and support, because you're afraid that they [will] take away what little there is.'(P12)

\section{Ineffective Support}

A number of participants described the support offered to them as not being particularly helpful. This included a view that people focused more on physical disabilities, or being given unhelpful advice when reporting the issues they were having, including:

'Stockholm is a boring university in a boring city [for studying abroad].

You should have gone to Uppsala.' (P1)

\section{Importance of Diagnosis}

A common theme was the perceived importance of an autism diagnosis to ensure access to appropriate support. Lack of diagnosis related to mood and social difficulties, having a diagnosis could be a catalyst for improvement:

'My diagnosis was corrected. My life changed completely. All of a sudden I can be a member of society, I am not completely unwanted after all.' (P2) 
'My life situation is much better now

than it was before I was diagnosed.' (P6)

\section{Theme 4: Specific Recommendations}

Participants made a number of suggestions for how other (future) students with autism could have a more positive university experience. The most salient theme was about relationships and the types of support that could be offered within them.

\section{Positive Relationships}

Participants highlighted the importance of positive relationships, whether with staff, support workers, family or friends.

\section{'Having more social support. Having consolidated friendships and a consistent and lasting social network.'(P5)}

In particular, staff need appropriate knowledge of support available, to be empathic, and relationships need to be consistent over time:

'A good support worker does not patronise but appreciates clients and their opinions and intellect.' (P8)

'He [needs to] always have the same people dealing with him, people who have enough time.' (P12)

Participants also mentioned the importance of career and employment support:

'Students need vocational guidance...there are many forms of professional development and if someone is not good in one area that should not affect the whole career.'(P13)

In terms of academic support, participants suggested a greater number of study advisors and more feedback on performance.

Individual Needs

Exploring individual needs when considering appropriate support to improve one's experience of university life and beyond, was also recommended. This may be financial, accommodation or skills related:

'It would be really good if someone here would take care of neuro-diverse university students holistically.' (P3) 
Participants suggested better development of skills related to planning and organization, group work, social skills and studying independently.

Academic Adjustments

Some participants suggested academic support adjustments that would have helped them during their time at university. They asked for more flexibility - or options - when it comes to being able to participate in learning and demonstrate understanding:

\section{'I wish the lecturers were flexible with the timing of my studies and the ways to show my skills' (P9)}

Flexibility in coursework arrangements, in terms of deadlines and mode of completion, was also recommended:

\section{'I should have had a chance to complete assignments alone instead of working in pairs.' (P7)}

What emerged was a sense that university ought to adapt to the student's needs and preferences, not the other way around.

\section{Discussion}

This study explored the HE experiences of students on the autism spectrum and generated a wide array of themes related to good and poor practice in support, social difficulties, struggles with mood and anxiety and the importance of positive personal relationships, as well as the need for autism awareness and empathy amongst professionals.

\section{Support}

Many of the difficulties reported here seem related to gaps in support and the view of autism as a barrier to success. This accords with the findings of previous studies (O'Neil, 2008; Plaisted Grant \& Davis, 2009) that students with autism and those who support them are not encouraged to consider positive aspects of their condition, that may help them at university and in later life.

Encouragingly, several participants reported they found it helpful to share their autism diagnosis and personal characteristics, evidencing a healthy level of self-advocacy and a positive attitude towards autism itself. These participants were then more inclined to connect problems they encountered with the lack of support and understanding, rather than with their condition. This further supports the observations by Anderson et al. (2017) and also by Pillay 
and Bhat (2012), that self-advocacy is a key catalyst for both accessing support and achieving academically.

Still related to the quality of support, participant responses clearly indicated that generic staff training and purely theoretical knowledge of autism were not sufficient to provide effective support. Support staff ideally have personal knowledge and experience of the kind of scenarios and experiences that can cause difficulties and have developed a high level of empathy, a demand echoed by Mitchell \& Beresford (2014). Conversely, participants thrived on positive, consistent support relationships, particularly with people who had appropriate knowledge of relevant services combined with a high level of autism awareness.

\section{Institutional Structure}

At a more systemic level, joined-up support and departmental collaboration emerged as key facilitators for study success, whilst the prevalent institutional separation between 'disability support' and 'academic support' emerged as a major barrier. We argue that the artificial split between the two types of support is not helpful as it increases the number of arrangements, appointments and people the student with autism has to deal with over time. Support needs to be joined up, covering all aspects of the university experience including life away from campus (Van Hees, Moyson, \& Roeyers, 2015). Focusing on a student's personal and academic strengths, engendering realistic expectations of student life, helping develop critical thinking skills and supporting perceived social weaknesses are all important parts of a support plan.

\section{Communication}

Somewhat related, communication was a recurring theme both in relation to good and poor support practice. The need for HE staff to convey appropriate information in an effective and coordinated manner was stressed. Where there was poor communication, problems quickly escalated. Some universities responded to a crisis by suggesting withdrawal from the course, deferring certain course elements or offering the student to repeat the year. While such advice was probably well-intended and grounded in a duty of care, in the instances reported the effects were not positive. It may be that for neurotypical students, time spent away from the university and in conversations with friends and family has a restorative effect. For students with autism, however, the sense of failure and the apprehension of returning to university into a group of unknown peers seemed to be corrosive to their self-esteem and their chances of success. 


\section{Relationships}

The importance of positive relationships with staff and student peers, and of belonging to a group, came up repeatedly. Social and relational difficulties impacted upon mood as well as studying experience and the ability to work productively, whether independently or with others. Where peer relationships were functioning, this had a distinctly positive effect on study success and emotional well-being, showing how far-reaching social aspects of the study experience are.

\section{Mood and Anxiety}

Worryingly, the majority of respondents $(n=13 ; 82 \%)$ struggled with their mood and emotional balance. Social isolation, exclusion, perceived hopelessness, depression and a feeling of disempowerment were repeatedly reported, mirroring observations by several other studies (Cassidy et al., 2014; Gelbar et al., 2014; Ward \& Webster, 2018). While for some the autism diagnosis was a positive revelation, for others it had negative consequences for their mental health, linked to the feeling of being different and excluded. Cassidy et al. (2014) found that people on the autism spectrum have many risk factors for secondary depression, potentially leading to suicide attempts, emphasizing the need for appropriate service planning and support to reduce risk factors in this student group.

\section{Reasonable Adjustments}

Some participants asked for reasonable adjustments in the form of flexibility with learning and assessment activities. An example given was group work, a common learning and assessment tool that does not generally suit students with autism' preferences (cf. Ward \& Webster, 2018). But finding reasonable alternatives to group work is arguably challenging as it risks openly marginalizing or stigmatizing the student in question.

Many participants described struggling to get used to university and 'the way things are done' in this new environment. Much of the existing procedures and supporting guidance puts the onus on the student to adapt, change and develop new organizational skills independently. This is despite the difficulty for students with autism in adapting to change, especially where anxiety levels are likely to be high already (Lawrence et al., 2010). It adds weight to the perception that in HE the disabled student is 'the problem', and not the institution.

\section{Resilience and Determination}

Generally though, students with autism had high aspirations, passion for their subject and showed remarkable resilience along the way, with many seeing the university experience as an opportunity to get deeply involved in their study topic and also to discover more about 
themselves. This aligns with observations by Ward \& Webster (2018) around high levels of determination and perseverance amongst university students with autism. However, for some these aspirations were disappointed when they realized their chosen subject area, or the style of teaching, did not match what they had anticipated.

\section{Reflection on themes}

The negative focus of themes that emerged from the data is perhaps not surprising.

Recognition of both the influence of our choice of questions and the way many participants chose to phrase their responses is why we chose not to take a more positive approach when framing our findings, similar to Vincent et al. (2016).

It should be pointed out that the identified themes are not unlike those reported by the wider student body entering HE (cf. Gale \& Parker (2014) for a list of transition dynamics). However, coping with negative experiences and resolving them through support networks seems to be considerably more challenging for students with autism.

Interestingly, the themes differ somewhat from those identified in a recent study by Lambe et al. (2019) which focused on the hopes and perspectives of students with autism before they started university. Whilst meeting academic demands and leaving the scaffolding of home were key themes pre-enrolment (cf. Lambe et al., 2019), issues surrounding support provision and the relationships with support staff and tutors play a much greater role once the course has started, as shown by the current study. This suggests that university does indeed allow students with autism to develop greater independence and self-determination. There is congruence between Lambe et al. and our findings regarding the social and practical aspects of the university experience - these key concerns do not seem to go away as study progresses.

\section{Conclusions}

The high levels of anxiety and mood difficulties experienced by our participants show that universities need to do more to understand how autism spectrum conditions can have an impact on students, and what they can do to alleviate this. They need to adjust their systems and practices in order to make them more flexible with regards to study modes, pathways and curricula.

The current predominant model asks the student to understand and adapt to an established environment, thereby locating the problem within the individual. Reasonable adjustments are typically offered, but without changing the core mode of teaching, learning and assessment. This is in contrast to policy based on the social model of disability which focuses on removing barriers, not remediating perceived deficits (Hewlett, Cooper, \& 
Jameson, 2018). Further, reasonable adjustments can separate students from their peers, increase social anxiety and exacerbate their sense of difference (Madriaga, 2010). Excluding, or 'othering' the student in this way does not promote inclusion in the university environment or encourage the institution and its people to change their practices (Atkinson et al., 2011).

We strongly believe such change is needed, very much in line with the concept of inclusive pedagogy which is gaining traction in compulsory education (Florian \& Beaton, 2018; Florian \& Spratt, 2013); a pedagogical approach that seeks to provide for everybody without further marginalizing or stigmatizing some as different. Applying this approach to HE curriculum design would, in our opinion, alleviate several of the negative learning experiences and social experiences encountered by the participants of this study.

Finally, Gale and Parker (2014) talk about going through higher education as 'becoming', recognizing the complexities of life and the interdependence of public issues and private troubles. Similarly, Vincent (2019) identifies the transition out of university as an important part of 'identity development', even though it often manifests itself through feelings of anxiety. This particular lens on the HE experience fits well with this study's student accounts which repeatedly returned to the topics of gaining independence, fulfilling aspirations, and completing their studies with growing determination and resilience.

\section{Recommendations}

There are a number of core recommendations we can draw directly from the above discussion, also incorporating participants' suggestions for better support in the future:

Table 3: Recommendations for educators

1. Learn about autism in general and about students' specific challenges and requirements. Undergo training in supporting autistic students and share outcomes with colleagues.

2. When being asked to make decisions about reasonable adjustments or special arrangements, consider instead what range of options can be given to ALL students. This way each student can choose the best way of acquiring and proving their knowledge and skills, and disabled students are not singled out.

3. Identify a student's strengths and find out how these can contribute to study situations.

4. Pro-actively provide support around students working in groups. Intervene when communication fails or any member of the group is excluded. Encourage the group to set "ground rules" right from the start. 
1. Ensure that those who support the student are suitably qualified and empathic towards the student's needs.

2. Join up social support and academic support where possible. Make support anticipatory rather than reactive. Teams often overlooked are security personnel and accommodation caretakers as these are often the first points of contact in a crisis.

3. Ensure that support arrangements are consistent wherever possible, i.e. the same person at the same time in the same place.

4. Avoid the need for students to have a formal diagnosis and disclose this to the university in order to gain access to support programs.

\section{Table 5: Recommendations for students}

1. Tell the university about your autism in order to access relevant support at the right time.

2. Learn to talk about your autism and to advocate for yourself. Know what makes you anxious and what will help you relax.

3. Identify your strengths and weaknesses and how these may affect typical study situations such as lectures, tutorials, group work and revision. Decide what you share with your student peers.

4. Identify quiet spaces on campus where you can relax when overloaded or to do your study. Try going into green spaces outdoors, going for a swim, or to the library.

\section{Strengths and Limitations of this Study}

This study deliberately explored stories of both success and failure, in line with the suggestion by Anderson et al. (2017). While responses originated from four Western countries (based on the residence of the person with autism: UK, Spain, Finland, USA), the analysis did not examine nationality or compare between countries and instead focused on common experiences. It is hoped that this provided the broadest range barriers and enablers. Whilst the experiences may not be representative of all countries in the world, we believe that the recommendations we have identified are generalizable enough to allow application in many other countries and contexts.

Participants tended to start their HE journeys in their late teens. This is representative of HE students in general, lending this study and its results external validity. Further, all 
participants reported a formal autism diagnosis, eliminating the possibility of skewed results due to incorrect self-diagnoses.

We checked for bias by those completing the survey on behalf of, and with, the person with autism. However, we did not find there to be a notable difference in the way that HE experiences were reported or judged by those third parties. We therefore felt it appropriate to report all results together.

Only 3 participants labelled their story a 'success', and this understandably led to a greater proportion of negative comments. However, in the context of trying to understand experiences and make recommendations to assist future students, we did not feel this was a validity issue.

Whilst the international dimension of the study can be considered a strength, response rates were still relatively low with only 16 participating. There is a risk that the study procedure introduced an element of self-selection bias, thereby suppressing the views representative of less vocal students who were either unable or unwilling to participate and of those who had more positive and supportive HE experiences. Future research aiming to gain a wider range of views could address this.

\section{A Note on Language}

We did not use autism labels as in our view it underestimates both the potential of those labelled as 'low-functioning' and the problems faced by those labelled as 'high-functioning', 'mild' or 'Asperger's'. Most people diagnosed with autism spectrum conditions have a 'spiky’ (Frith \& Happé, 1994) and inconsistent IQ profile, with skills and deficits in different areas and even at different times of the day. The participants of this study aimed for a HE qualification, and they also told us that they have an autism spectrum condition. No other labels were necessary in order to understand their responses.

\section{Acknowledgements}

This work was supported by the European Commission's Lifelong Learning Programme under Grant number 539031-LLP-1-2013-1-UK-ERASMUS-ESIN. We are indebted to the enthusiasm and openness of our participants when sharing their personal stories. Thanks also to Sarah Asquith for her assistance with data analysis to ensure inter-rater reliability. A more comprehensive set of recommendations and examples of good support practice are available from the Autism\&Uni project website (www.autism-uni.org/bestpractice).

\section{Declaration of Interest Statement}

The authors declare that they have no conflict of interest. 


\section{Ethical Approval}

The study received approval from the institutional Research Ethics Committee at Leeds Beckett University. It is in compliance with the 1964 Helsinki declaration and its later amendments.

\section{References}

Anderson, A. H., Stephenson, J., \& Carter, M. (2017). A systematic literature review of the experiences and supports of students with autism spectrum disorder in post-secondary education. Research in Autism Spectrum Disorders, 39, 33-53. https://doi.org/10.1016/j.rasd.2017.04.002

Atkinson, R., Gandy, C., Graham, C., Hendrickx, S., Jackson, V., Martin, N., \& Rainford, L. (2011). Aspects of Social interaction and Buddy Scheme-Supporting Transition and Progression for Students Identified with Asperger Syndrome. Journal of Inclusive Practice in Further and Higher Education, 3(2), 109-124.

Bakker, T., Krabbendam, L., Bhulai, S., \& Begeer, S. (2019). Background and enrollment characteristics of students with autism in higher education. Research in Autism Spectrum Disorders, 67, 101424. https://doi.org/10.1016/j.rasd.2019.101424

Braun, V., \& Clarke, V. (2006). Using thematic analysis in psychology. Qualitative Research in Psychology, 3(2), 77-101. https://doi.org/10.1191/1478088706qp063oa

Brugha, T., Cooper, S. A., McManus, S., Purdon, S., Smith, J., Scott, F. J., ... Tyrer, F. (2012). Estimating the Prevalence of Autism Spectrum Conditions in Adults: Extending the 2007 Adult Psychiatric Morbidity Survey (p. 31). Retrieved from The NHS Information Centre website: https://digital.nhs.uk/data-andinformation/publications/statistical/estimating-the-prevalence-of-autism-spectrumconditions-in-adults/estimating-the-prevalence-of-autism-spectrum-conditions-inadults-extending-the-2007-adult-psychiatric-morbidity-survey

Cai, R. Y., \& Richdale, A. L. (2016). Educational Experiences and Needs of Higher Education Students with Autism Spectrum Disorder. Journal of Autism and Developmental Disorders, 46(1), 31-41. https://doi.org/10.1007/s10803-015-2535-1

Cassidy, S., Bradley, P., Robinson, J., Allison, C., McHugh, M., \& Baron-Cohen, S. (2014). Suicidal ideation and suicide plans or attempts in adults with Asperger's syndrome attending a specialist diagnostic clinic: A clinical cohort study. The Lancet Psychiatry, 1(2), 142-147. https://doi.org/10.1016/S2215-0366(14)70248-2 
Centers for Disease Control and Prevention. (2018, April 26). Autism prevalence slightly higher in CDC's ADDM Network. Retrieved October 9, 2019, from https://www.cdc.gov/media/releases/2018/p0426-autism-prevalence.html

Elliott, R., Fischer, C. T., \& Rennie, D. L. (1999). Evolving guidelines for publication of qualitative research studies in psychology and related fields. British Journal of Clinical Psychology, 38(3), 215-229. https://doi.org/10.1348/014466599162782

Florian, L., \& Beaton, M. (2018). Inclusive pedagogy in action: Getting it right for every child. International Journal of Inclusive Education, 22(8), 870-884. https://doi.org/10.1080/13603116.2017.1412513

Florian, L., \& Spratt, J. (2013). Enacting inclusion: A framework for interrogating inclusive practice. European Journal of Special Needs Education, 28(2), 119-135. https://doi.org/10.1080/08856257.2013.778111

Fombonne, E. (2009). Epidemiology of Pervasive Developmental Disorders. Pediatric Research, 65(6), 591-598. https://doi.org/10.1203/PDR.0b013e31819e7203

Frith, U., \& Happé, F. (1994). Autism: Beyond "theory of mind.” Cognition, 50.

Gale, T., \& Parker, S. (2014). Navigating change: A typology of student transition in higher education. Studies in Higher Education, 39(5), 734-753. https://doi.org/10.1080/03075079.2012.721351

Gelbar, N. W., Smith, I., \& Reichow, B. (2014). Systematic Review of Articles Describing Experience and Supports of Individuals with Autism Enrolled in College and University Programs. Journal of Autism and Developmental Disorders, 44(10), 2593 2601. https://doi.org/10.1007/s10803-014-2135-5

HESA. (2018). HE Student Data | HESA. Retrieved April 29, 2019, from HE Student Data website: https://www.hesa.ac.uk/data-and-analysis/students

Hewlett, K., Cooper, R., \& Jameson, M. (2018). Neurodiverse voices: Opening Doors to Employment (p. 36). Retrieved from Westminster AchieveAbility Commission for Dylexia and Neurodivergence website: https://www.achieveability.org.uk/files/1516612947/wac-neurodiverse-voicesopening-doors-to-employment-report_2018_interactive.pdf

Lambe, S., Russell, A., Butler, C., Fletcher, S., Ashwin, C., \& Brosnan, M. (2019). Autism and the transition to university from the student perspective. Autism, 23(6), 15311541. https://doi.org/10.1177/1362361318803935 
Lawrence, D. H., Alleckson, D. A., \& Bjorklund, P. (2010). Beyond the Roadblocks: Transitioning to Adulthood With Asperger's Disorder. Archives of Psychiatric Nursing, 24(4), 227-238. https://doi.org/10.1016/j.apnu.2009.07.004

Madriaga, M. (2010). 'I avoid pubs and the student union like the plague': Students with Asperger Syndrome and their negotiation of university spaces. Children's Geographies, 8(1), 39-50. https://doi.org/10.1080/14733280903500166

Milton, D., \& Sims, T. (2016). How is a sense of well-being and belonging constructed in the accounts of autistic adults? Disability \& Society, 31(4), 520-534. https://doi.org/10.1080/09687599.2016.1186529

Mitchell, W., \& Beresford, B. (2014). Young people with high-functioning autism and Asperger's syndrome planning for and anticipating the move to college: What supports a positive transition? British Journal of Special Education, 41(2), 151-171. https://doi.org/10.1111/1467-8578.12064

Ness, B. M. (2013). Supporting Self-Regulated Learning for College Students with Asperger Syndrome: Exploring the "Strategies for College Learning” Model. Mentoring \& Tutoring: Partnership in Learning, 21(4), 356-377. https://doi.org/10.1080/13611267.2013.855865

O’Neil, S. (2008). The meaning of autism: Beyond disorder. Disability \& Society, 23(7), 787-799. https://doi.org/10.1080/09687590802469289

Pillay, Y., \& Bhat, C. S. (2012). Facilitating Support for Students with Asperger's Syndrome. Journal of College Student Psychotherapy, 26(2), 140-154. https://doi.org/10.1080/87568225.2012.659161

Plaisted Grant, K., \& Davis, G. (2009). Perception and apperception in autism: Rejecting the inverse assumption. Philosophical Transactions of the Royal Society of London. Series B, Biological Sciences, 364(1522), 1393-1398. https://doi.org/10.1098/rstb.2009.0001

QSR International. (2015). NVivo qualitative data analysis software (Version 11). Retrieved from https://www.qsrinternational.com/nvivo/home

Rogge, N., \& Janssen, J. (2019). The Economic Costs of Autism Spectrum Disorder: A Literature Review. Journal of Autism and Developmental Disorders, 49(7), 28732900. https://doi.org/10.1007/s10803-019-04014-z

Russell, G., Kapp, S. K., Elliott, D., Elphick, C., Gwernan-Jones, R., \& Owens, C. (2019). Mapping the Autistic Advantage from the Accounts of Adults Diagnosed with Autism: 
A Qualitative Study. Autism in Adulthood, 1(2), 124-133.

https://doi.org/10.1089/aut.2018.0035

Snap Surveys. (2010). Snap Survey Software v10 (Version 10). Retrieved from http://www.snapsurveys.com/

Van Hees, V., Moyson, T., \& Roeyers, H. (2015). Higher Education Experiences of Students with Autism Spectrum Disorder: Challenges, Benefits and Support Needs. Journal of Autism and Developmental Disorders, 45(6), 1673-1688.

https://doi.org/10.1007/s10803-014-2324-2

Vincent, J. (2019). It's the fear of the unknown: Transition from higher education for young autistic adults. Autism. https://doi.org/10.1177/1362361318822498

Vincent, J., Potts, M., Fletcher, D., Hodges, S., Howells, J., Mitchell, A., ... Ledger, T. (2016). 'I think autism is like running on Windows while everyone else is a Mac': Using a participatory action research approach with students on the autistic spectrum to rearticulate autism and the lived experience of university. Educational Action Research, 25(2), 300-315. https://doi.org/10.1080/09650792.2016.1153978

Ward, D., \& Webster, A. (2018). Understanding the Lived Experiences of University Students with Autism Spectrum Disorder (ASD): A Phenomenological Study. International Journal of Disability, Development and Education, 65(4), 373-392. https://doi.org/10.1080/1034912X.2017.1403573

Wehman, P., Schall, C., Carr, S., Targett, P., West, M., \& Cifu, G. (2014). Transition From School to Adulthood for Youth With Autism Spectrum Disorder: What We Know and What We Need to Know. Journal of Disability Policy Studies, 25(1), 30-40. https://doi.org/10.1177/1044207313518071 